\title{
Overflow proteinuria as a manifestation of unrecognized polymyositis
}

This article was published in the following Dove Press journal:

International Medical Case Reports Journal

I April 2014

Number of times this article has been viewed

\author{
Hyun Ho Kim' \\ Jae Young Kim' \\ Sung Jun Kim ${ }^{1,2}$ \\ Eun Su Park ${ }^{3}$ \\ Seok Joon Shin ${ }^{1,2}$ \\ Kwi Young Kang ${ }^{1,4}$ \\ Yeon Sik Hong ${ }^{1,4}$ \\ Hye Eun Yoon ${ }^{1,2}$
}

'Department of Internal Medicine, College of Medicine, The Catholic University of Korea, ${ }^{2}$ Division of Nephrology, Department of Internal Medicine, Incheon St Mary's Hospital, ${ }^{3}$ Department of Pathology, Incheon St Mary's Hospital, ${ }^{4}$ Division of Rheumatology, Department of Internal Medicine, Incheon St Mary's Hospital, Incheon, Republic of Korea
Correspondence: Hye Eun Yoon Department of Internal Medicine, Incheon St Mary's Hospital, College of Medicine, The Catholic University of Korea, 56 Dongsu-ro, Pupyung-gu, Incheon, Republic of Korea

Tel +82 322805886

Fax +82 322805987

Email berrynana@catholic.ac.kr

\begin{abstract}
Polymyositis is a rare and gradually progressive autoimmune disease of skeletal muscle. Two main types of renal involvement have been described: acute tubular necrosis related to rhabdomyolysis and glomerulonephritis. However, cases of overflow proteinuria related to polymyositis have rarely been reported. Herein, we report a case of a 41 -year-old male who presented with edema of both lower extremities. Laboratory studies revealed elevated creatine phosphokinase level, hypoalbuminemia, and a moderate amount of proteinuria, although albuminuria was not dominant. Urine electrophoresis showed an abnormally restricted zone in the $\beta$-fraction, which suggested overflow proteinuria of non-glomerular origin. Despite intravenous hydration, his serum creatine phosphokinase level did not decrease and his symptoms did not improve. Electromyography showed myopathy, and muscle biopsy revealed findings consistent with polymyositis. After corticosteroid therapy, his creatine phosphokinase level and proteinuria decreased and his clinical symptoms improved. This case demonstrates an atypical presentation of polymyositis manifested by overflow proteinuria.
\end{abstract}

Keywords: polymyositis, proteinuria, rhabdomyolysis

\section{Introduction}

Polymyositis is a rare and gradually progressive autoimmune disease of skeletal muscle. ${ }^{1}$ Two main types of renal involvement have been described: acute tubular necrosis related to rhabdomyolysis and glomerulonephritis. ${ }^{2}$ Previous reports have demonstrated glomerular proteinuria in polymyositis; however, overflow proteinuria associated with rhabdomyolysis secondary to polymyositis is not well-described. Herein, we report a case of polymyositis presenting with edema of both lower extremities, which was associated with hypoalbuminemia and a moderate amount of proteinuria of non-glomerular origin.

\section{Case report}

A 41-year-old man visited our clinic with swelling and weakness of both lower extremities of 1-month duration. Recently, he had begun to have pain in both thighs and difficulty in lifting his legs. He had no history of recent trauma, administration of drugs, infections, physical exercise, endocrinopathies, or other factors that could cause rhabdomyolysis. On physical examination, there was pitting edema of the lower extremities without cutaneous eruption. Table 1 shows the laboratory data. He recently noticed that his urine was tea-colored. The urine dipstick showed a positive test for blood in the absence of red cells in the sediment. The spot urine protein-to-creatinine ratio was $1,714 \mathrm{mg} / \mathrm{g}$. His serum myoglobin was $0.405 \mathrm{mg} / \mathrm{dL}$ and urine myoglobin 
Table I Laboratory values

\begin{tabular}{|c|c|c|}
\hline Variable & Result & Normal value \\
\hline Haemoglobin $(\mathrm{g} / \mathrm{dL})$ & 11.7 & |3.4 17.4 \\
\hline Hematocrit (\%) & 34.2 & $39 \sim 51$ \\
\hline Protein $(\mathrm{g} / \mathrm{dL})$ & 7.6 & $6.7 \sim 8.4$ \\
\hline Albulmin (g/dL) & 2.9 & $3.8 \sim 5.1$ \\
\hline Aspartate aminotransferase (U/L) & 1,017 & $9 \sim 40$ \\
\hline Alanine aminotransferase (U/L) & 608 & $0 \sim 40$ \\
\hline Creatine phosphokinase (IU/L) & 18,155 & $0 \sim 250$ \\
\hline Lactic acid dehydrogenase (IU/L) & 3,476 & $208 \sim 450$ \\
\hline Urea nitrogen (mg/dL) & 12.6 & $8 \sim 24$ \\
\hline Creatinine (mg/dL) & 0.5 & $0.5 \sim 1.2$ \\
\hline Sodium (mEq/L) & 134 & $136 \sim 145$ \\
\hline Potassium (mEq/L) & 4.2 & $3.5 \sim 5.1$ \\
\hline Calcium (mg/dL) & 7.9 & $8.5 \sim 10.2$ \\
\hline Phosphorus (mg/dL) & 4.6 & $2.7 \sim 5.1$ \\
\hline Uric acid (mg/dL) & 4.7 & $3.5 \sim 8$ \\
\hline Total cholesterol (mg/dL) & 119 & $120 \sim 245$ \\
\hline LDL-cholesterol (mg/dL) & 76 & $60 \sim 150$ \\
\hline HDL-cholesterol (mg/dL) & 18 & $32 \sim 75$ \\
\hline Triglyceride (mg/dL) & 125 & $5 \sim 170$ \\
\hline
\end{tabular}

Abbreviations: LDL, low-density lipoprotein; HDL, high-density lipoprotein.

was undetectable. Aggressive volume replacement was started for the treatment of rhabdomyolysis.

A 24-hour urine collection showed protein excretion of $3,140 \mathrm{mg} /$ day and albumin excretion of $122.5 \mathrm{mg} /$ day. Albuminuria was $3.9 \%$ of total proteinuria. The electrophoretic analysis of the serum and urine proteins is shown in Figure 1. The serum electrophoresis pattern showed decreased albumin and increased $\alpha 1$-fraction, $\beta$-fraction, and $\gamma$-globulins, suggesting polyclonal gammopathy (Figure 1A). The urine electrophoresis showed increased $\beta$-fraction, which accounted for $53.3 \%$ of the urinary proteins (Figure 1B).

A

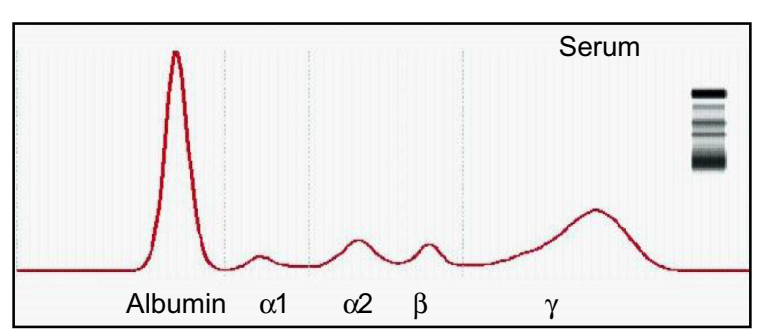

B

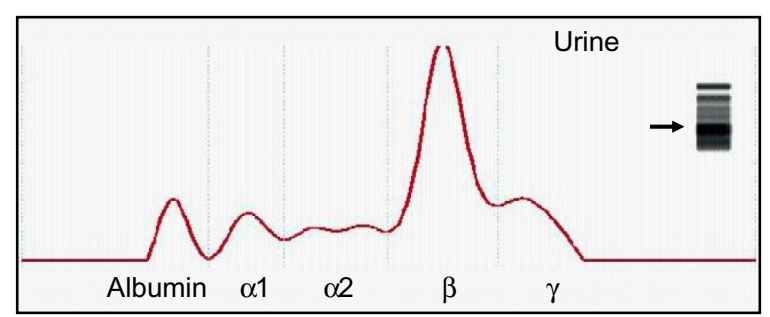

Figure I Electrophoresis of serum (A) and urine (B). The arrow in the urine electrophoresis indicates the pathological homogenous component that accounted for $53.3 \%$ of the urinary proteins in the $\beta$-fraction.
Immunofixation of serum and urine was performed to identify monoclonal immunoglobulins and/or free light chains, and gave negative results. Despite fluid replacement, the patient's creatine phosphokinase (CPK) level increased to $21,450 \mathrm{IU} / \mathrm{L}$ and his leg weakness did not improve. Nerve conduction studies were normal but the electromyography showed short-duration, low-amplitude, and polyphasic patterns in all of the left upper and lower extremity muscles, suggesting inflammatory myopathy. The test for anti-Jo-1 antibody was positive, with a titer more than $8.0 \mathrm{EU}$. Biopsy of the left vastus lateralis muscle demonstrated endomysial chronic inflammation and muscle fiber necrosis (Figure 2A), and immunohistochemical stain showed infiltration by $\mathrm{CD} 8+$ $\mathrm{T}$ cells (Figure 2B). Polymyositis was diagnosed by the criteria of Bohan and Peter, ${ }^{3}$ as he had symmetric proximal muscle weakness, histologic evidence of myositis, elevated serum muscle enzymes, and characteristic myopathic changes on electromyography, without skin changes. The patient
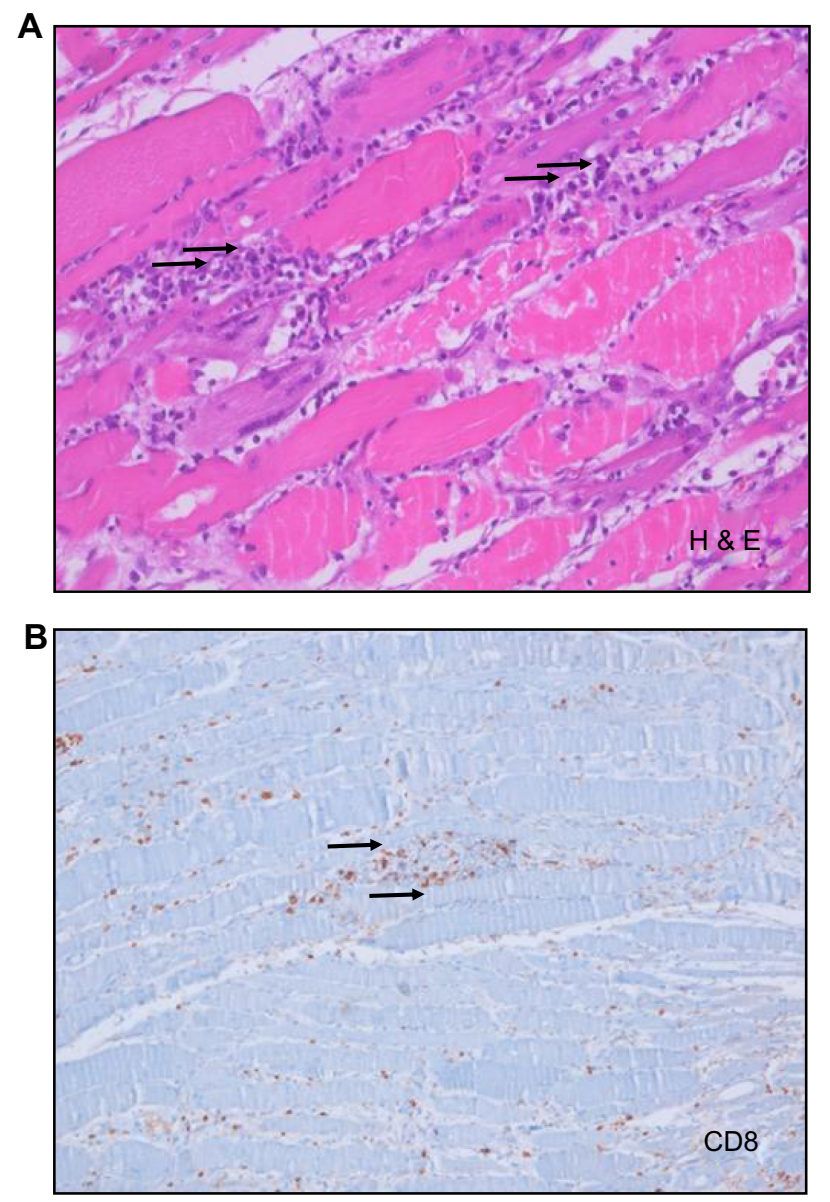

Figure 2 Thigh muscle biopsy.

Notes: (A) Inflammatory cells invading the endomysium within the muscle fascicles (arrows). Hematoxylin and eosin stain $(\times 200$ magnification). (B) Immunohistochemical staining for CD8. Activated CD8+ T cell lymphocytes have infiltrated the vastus lateralis muscle ( $\times 100$ magnification, brown color, arrows). 
was started on prednisone, $1 \mathrm{mg} / \mathrm{kg}$ daily, which resulted in gradual improvement of his leg pain, weakness, and swelling. After 1 month, his CPK level decreased to $461 \mathrm{IU} / \mathrm{L}$ and the spot urine protein-to-creatinine ratio decreased to $24.1 \mathrm{mg} / \mathrm{g}$.

\section{Discussion}

This case describes a patient with polymyositis who presented with edema of the lower extremities because of overflow proteinuria of non-glomerular origin, which was demonstrated by the electrophoresis of urine. Polymyositis is a rare and gradually progressive autoimmune disease of skeletal muscle. ${ }^{1}$ The two main renal manifestations of polymyositis are known as acute kidney injury (AKI) secondary to rhabdomyolysis ${ }^{2,4,5}$ and polymyositis-associated glomerulonephritis. ${ }^{2,6-8}$ However, overflow proteinuria with rhabdomyolysis has been rarely described. Our patient exhibited hypoalbuminemia and a moderate amount of proteinuria of non-glomerular origin without acute AKI. Although prompt aggressive fluid replacement was started, his CPK levels increased dramatically. As the patient had muscle weakness and myalgia, inflammatory myopathy would be one of the possible conditions in this case. This case implies that muscle weakness and myalgia should not be overlooked in patients with rhabdomyolysis.

Patients with rhabdomyolysis may exhibit proteinuria of varying degrees. This is because of the overflow excretion of urinary myoglobin and low molecular weight proteins and the altered glomerular permeability induced by either myoglobin or other substances released from muscles. ${ }^{9}$ Rhabdomyolysis rarely develops in patients with polymyositis, ${ }^{10}$ and about $6 \%$ of patients have CPK levels higher than 3,000 IU/L, ${ }^{11}$ as was found in the present case. In patients with polymyositis, proteinuria is related to various types of glomerulonephritis, ${ }^{2,6-8}$ or myoglobinuria. ${ }^{2}$ As the patient had hypoalbuminemia and a moderate amount of proteinuria, we initially expected the proteinuria was of a glomerular origin. It was reported that renal involvement occurred in $23.3 \%$ of patients with inflammatory myopathy. ${ }^{12}$ Therefore, glomerulonephritis might have been combined in this case, and the lack of renal biopsy is a limitation of our report. However, albuminuria accounted for only $3.9 \%$ of total proteinuria and our patient did not have dyslipidemia, which is unusual in nephrotic syndrome. The electrophoretic analysis of his urine showed that most of the urinary protein was restricted to the $\beta$-fraction, not to the albumin fraction. This suggested that the proteinuria was of non-glomerular origin. ${ }^{13}$ Recently, Rostagno and Ghiso reported a case of myoglobinuria associated with rhabdomy- olysis exhibiting a similar pattern of urine electrophoresis to that in our patient. ${ }^{14}$ The authors demonstrated that the predominant homogenous urinary band in the $\beta$-fraction showed a high immunoreactivity with anti-myoglobin antibody and the molecular mass was $17,053.1 \mathrm{Da}$, which corresponds to the molecular mass of myoglobin. ${ }^{15}$ Therefore, we speculate that in this case, the urinary proteins in the predominant $\beta$-fraction were probably myoglobins and other low molecular weight proteins, which resulted in overflow proteinuria. In this case, urine dipstick showed a positive test for blood, but urine myoglobin was not detected. This is because myoglobin rapidly disappears in plasma by hepatic metabolism, ${ }^{16,17}$ and myoglobin begins to be detected in the urine when the plasma concentration exceeds $1.5 \mathrm{mg} / \mathrm{dL} .^{18}$ Patients with polymyositis are reported to have moderately raised concentrations of serum myoglobin but not overt myoglobinuria. ${ }^{19}$ As the serum myoglobin level in our patient was $0.405 \mathrm{mg} / \mathrm{dL}$, the level of urine myoglobin might not have been sufficient to be detected.

In summary, this case shows that polymyositis can be accompanied by overflow proteinuria although overt myoglobinuria is absent. The diagnosis of polymyositis must be considered in patients with rhabdomyolysis and muscle weakness, and biochemical analysis of the accompanied proteinuria may help to identify the type of renal involvement in this rare disease. Early recognition and prompt immunosuppressive therapy are essential to prevent kidney injury in these patients.

\section{Acknowledgments}

This report was approved by the Institutional Review Board of the Catholic University of Korea (OC13ZISE0150). This research was supported by the Basic Science Research Program through the National Research Foundation of Korea (NRF) funded by the Ministry of Science, ICT, and Future Planning (20110013312).

\section{Disclosure}

The authors report no conflicts of interest in this work.

\section{References}

1. Mammen AL. Dermatomyositis and polymyositis: clinical presentation, autoantibodies, and pathogenesis. Ann NY Acad Sci. 2010;1184: 134-153.

2. Yen TH, Lai PC, Chen CC, Hsueh S, Huang JY. Renal involvement in patients with polymyositis and dermatomyositis. Int J Clin Pract. 2005;59(2):188-193.

3. Bohan A, Peter JB. Polymyositis and dermatomyositis. $N$ Eng $J$ Med. 1975;292(7):344-347.

4. Tsai CN, Liu MF, Lin TS, Lin LH, Wang CR. Rhabdomyolysis and acute renal failure in a polymyositis patient. Mod Rheumatol. 2004;14(5): $422-423$. 
5. Kim HW, Choi JR, Jang SJ, Chang YS, Bang BK, Park CW. Recurrent rhabdomyolysis and myoglobinuric acute renal failure in a patient with polymyositis. Nephrol Dial Transplant. 2005;20:2255-2258.

6. Stefanidis I, Giannopoulou M, Liakopoulos V, et al. A case of membranous nephropathy associated with Sjögren syndrome, polymyositis and autoimmune hepatitis. Clin Nephrol. 2008;70(3):245-250.

7. Takizawa Y, Kanda H, Sato K, et al. Polymyositis associated with focal mesangial proliferative glomerulonephritis with depositions of immune complexes. Clin Rheumatol. 2007;26(5):792-796.

8. Evron E, Abarbanel JM, Branski D, Sthoeger ZM. Polymyositis, arthritis, and proteinuria in a patient with adult celiac disease. J Rheumatol. 1996;23(4):782-783.

9. Zager RA. Rhabdomyolysis and myohemoglobinuric acute renal failure. Kidney Int. 1996;49:314-326.

10. Carleton H, Pitts W, Davidson W, Roth P. Muscle disease associated with renal failure. Arch Intern Med. 1977;137:939-941.

11. Targoff IN. Laboratory manifestations of polymyositis/dermatomyositis. Clin Dermatol. 1988;6(2):76-92.
12. Couvrat-Desvergnes G, Masseau A, Benveniste O, et al. The spectrum of renal involvement in patients with inflammatory myopathies. Medicine (Baltimore). 2014;93(1):33-41.

13. Viswanathan G, Upadhyay A. Assessment of proteinuria. Adv Chronic Kidney Dis. 2011;18(4):243-248.

14. Rostagno A, Ghiso J. Biochemical analysis of myoglobinuria associated with rhabdomyolysis. Acta Bioquim Clín Latinoam. 2013;47(1):17-24.

15. Hamilton RW, Hopkins MB, Shihabi ZK. Myoglobinuria, hemoglobinuria, and acute renal failure. Clin Chem. 1989;35(8):1713-1720.

16. Raymond V, Mehmet SS, Ekrem E, Norbert L. Rhabdomyolysis. J Am Soc Nephrol. 2000;11:1553-1561.

17. Lin AC, Lin CM, Wang TL, Leu JG. Rhabdomyolysis in 119 students after repetitive exercise. Br J Sports Med. 2005;39(1):e3.

18. Bagley WH, Yang H, Shah KH. Rhabdomyolysis. Intern Emerg Med. 2007;2(3):210-218.

19. Sieb JP, Penn AS. Myoglobinuria. In: Engel AG, Franzini-Armstrong C, editors. Myology. New York: McGraw-Hill; 2004:1677-1692.
International Medical Case Reports Journal

\section{Publish your work in this journal}

The International Medical Case Reports Journal is an international, peer-reviewed open-access journal publishing original case reports from all medical specialties. Previously unpublished medical posters are also accepted relating to any area of clinical or preclinical science. Submissions should not normally exceed 2,000 words or

\footnotetext{
Submit your manuscript here: http://www.dovepress.com/international-medical-case-reports-journal-journal
}

4 published pages including figures, diagrams and references. The manuscript management system is completely online and includes a very quick and fair peer-review system, which is all easy to use. Visit $\mathrm{http}: / /$ www.dovepress.com/testimonials.php to read real quotes from published authors. 